\title{
Cena
}

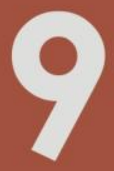

Dossiê Dança em Desdobramentos

PERIÓDICO DO PROGRAMA DE PÓS-GRADUAÇĀO EM ARTES CÊNICAS

INSTITUTO DE ARTES | DEPARTAMENTO DE ARTE DRAMÁTICA

UNIVERSIDADE FEDERAL DO RIO GRANDE DO SUL

\section{CORPO DA CONSCIÊNCIA E POSSÍVEIS \\ DRAMATURGIAS DA MEMÓRIA QUE DANÇA}

Patrícia Leonardelli ${ }^{1}$

\footnotetext{
1 Pós-doutoranda no grupo LUME - Núcleo Interdisciplinar de Pesquisas Teatrais da Unicamp. Doutorado em Artes pela Universidade de São Paulo.
} 
RESUMO: Nosso texto pretende discutir alguns pontos-chave da problemática de dramaturgia em Dança a partir das noções de memória como recriação do vivido e fluxo de atualizações e virtualizações em devir, proposta por Gilles Deleuze, e de corpo da consciência apresentada por José Gil. A partir dessa interlocução epistemológica, desejamos indicar alguns caminhos teóricos que auxiliem na revisão do conceito de dramaturgia, em que o corpo surge como o território das sínteses dinâmicas que problematizam, mas também ampliam, as possibilidades semânticas de trabalho com a palavra.

PALAVRAS-CHAVE: Memória; Corpo-em-arte; Dramaturgia; Movimento; Dança.

ABSTRACT: Our paper seeks to discuss some key points of the issue of Dance drama based on the notions of memory as a recreation of the lived and flow of updates and virtualization, proposed by Gilles Deleuze and body awareness by Jose Gil. From this epistemological dialogue, wish to point out some theoretical ways to assist in reviewing the concept of drama, in which the body appears to be the territory of dynamic syntheses that question, but also extend the semantic possibilities of working with the word.

KEYWORDS: Memory; Body-in-art; Dramaturgy; Movement; Dance.

Nosso artigo pretende retomar algumas questões centrais do debate sobre dramaturgia em Dança à luz da noção de corpo do pensamento, proposta por José Gil, e de memória criadora, de Gilles Deleuze, para daí sugerir possíveis redefinições nos desenhos daquilo que mais comumente reconhecemos como dramaturgia strictu sensu. Para tanto, é necessário que, primeiro, repensemos a criação em dramaturgia (e seu espaço) como um processo que se dá tanto no âmbito do encontro dos artistas-criadores como da performatividade como campo em suspensão.

Partamos de algumas definições históricas de dramaturgia em Dança pela perspectiva de criadores-chave da disciplina. Marianne van Kherkoven, uma das mais produtivas pesquisadoras da área (foi colaboradora dos coreógrafos Jan Lauwers / Needcompany, Guy Cassiers, Anne Teresa de Keersmaeker e Kris Verdonck) e editora das revistas Theaterschrift e Etcetera, especializadas em Dança e Teatro Pós-dramático, pontua a questão da construção e da natureza dos materiais. Enquanto a dramaturgia 
em Teatro partiria geralmente de um texto, ou de um tema a partir do qual evolui o enredo ${ }^{1}$, a mesma disciplina, quando trabalhada na Dança, tomaria como estímulo fundamental a música ou os movimentos dos dançarinos, o que define operacionalidades distintas nos processos de criação.

A escrita teatral, entendida como peça, conforme a dramaturga, estaria pressionada, pelas próprias singularidades do fazer teatral, a se estruturar dentro de uma dinâmica de significação, de construção de sentidos, de contar histórias, à qual a Dança moderna e contemporânea não se submete. Enquanto as ações, gestos, deslocamentos, enfim, desenhos físicos do ator em cena aproximam sua construção (a personagem) do comportamento cotidiano, a abstração de movimentos permitida pela Dança provoca, às palavras de Kerkhoven, o trabalho do dramaturgo a se deixar afetar por outras contaminações sutis, intuitivas, não-denotativas, analógicas, ou que nome queiramos dar a um fluxo de afetações que se reterritorializa para zonas de representações fugidias, de rastros de sentido, de devires velozes que parecem se esquivar da semiotização.

Eis a primeira e mais imediata diferenciação histórica do conceito quando trabalhado nas duas áreas. Como sabemos, a Dança, no cerne de seu próprio processo de emancipação como linguagem, que marca a passagem dessa arte do estatuto clássico para aquele moderno, exigiu sua autonomia da narrativa e do drama como condição sine qua non de evolução. A dramaturgia acompanhou essa ruptura seminal e fundou um campo de pesquisa que explora a produção do texto em condições amplamente diversificadas, e abriu espaço para toda escrita fundada em/por processos híbridos da cena.

A essa problemática inicial levantada por Kerkhoven, o também dramaturgo Antoine Pickels acrescenta uma questão fundamental: a participação do bailarino/intérprete-criador nessa atividade. Pickels reflete sobre o paradoxo, em certa medida, inconciliável entre as duas atividades: 0 trabalho do corpo-em-arte que dança e aquele que escreve. Tratam-se de estados e disposições para sistematizar seus discursos que produzem nexos, de fato, muito, distintos, mas que podem se beneficiar precisamente

\footnotetext{
${ }^{1}$ Ela se refere, evidentemente, ao teatro dramático.
} 
dessas diferenças. O corpo que dança trabalha numa velocidade de agenciamentos muita mais alta do que o corpo que escreve. Não falamos aqui de velocidade na execução da coreografia, ou da improvisação, que pode ser visualmente desacelerada, mas da dinâmica própria da Dança de desvio das linguagens convencionais do corpo, ou, pelo menos, de contaminação dessas linguagens pelo seu atravessamento por movimentos intraduzíveis, não-denotativos, que pressionam o que é dançado exatamente para a fronteira da linguagem como a reconhecemos. E, nesse sentido, para Pickels, está claro que o corpo que dança é, em grande parte, inapreensível à palavra e ao estatuto da dramaturgia, ao qual não deve se submeter para normatizar sua potência de criação.

Entretanto, esses corpos que dançam também podem organizar seus discursos, da mesma forma que um corpo que escreve pode se deixar atravessar por forças criadoras que o façam transgredir os modelos dramatúrgicos convencionais e inventar novos suportes e formatos para 0 trabalho com a palavra nesses contextos. De forma que, apenas com a contribuição desses dois criadores, já é possível abordar algumas questões essenciais de nosso debate.

Se insistirmos em uma cisão da dramaturgia por disciplina, é inevitável que atentemos para o delicado e precário equilíbrio hierárquico que parece acompanhar as relações entre Dança e dramaturgia tanto quanto desta última com o Teatro. Porém, é possível pensarmos o trabalho dramatúrgico por outra perspectiva, de certa forma, intrínseca ao próprio fazer, e que busca as zonas de avizinhamento entre as atividades do dramaturgo de Dança, do dramaturgo em Teatro, do ator e do dançarino. Trata-se de não pensar mais os corpos criadores em questão a partir da área em que se encaixam, mas, primeiramente, por sua condição de corposem-arte criando e sistematizando discursos mais ou menos convencionais (no sentido de reconhecíveis), em desenhos singulares. Dessa forma, a dramaturgia surge como produto de vivências de criação que já nascem assumidamente "em fronteira", e cujas singularidades expressivas se filiam às dinâmicas específicas de cada processo, e não numa aproximação forçosa com determinada área e seus modelos de escrita (texto dramático 
para o Teatro, texto dramático para a Dança, texto pós-dramático para Performance, ou para a Dança, etc.). Pensemos como isso é possível.

Como já afirmamos, o corpo que dança sintetiza conhecimento em condições profundamente distintas do corpo que escreve, e o traduz em formas igualmente diferenciadas, senão opostas. Enquanto o corpo que escreve busca construir significados e traduzi-los em uma língua, o corpo que dança se encaminha para o esvaziamento de todo sentido apriorístico que implica na pesquisa sobre o movimento puro em si. São processos absolutamente particulares, orientados por agenciamentos e dinâmicas diametralmente opostos, mas que se provocam e atravessam quando confrontados; e que se utilizam de uma base comum, qual seja, os próprios corpo dos bailarinos e dramaturgos como estratos orgânicos, históricos e criadores em devir. O filósofo José Gil, em sua obra de referência Movimento Total - O Corpo e a Dança, analisa, na passagem abaixo, precisamente o efeito da velocidade dos atravessamentos e sínteses envolvidas no trabalho do corpo que dança, e como tal dinâmica pressiona para o esvaziamento, vazio, este, que se preenche por uma nova noção de articulação:

Não há 'gestemas' discretos, comparáveis aos monemas, nem unidades inseparáveis não-significativas, como os fonemas. Daí a inexistência de uma dupla articulação de uma linguagem do corpo, à maneira da linguagem falada. (...) O corpo comum exprime um sentido, embora não por meio de uma linguagem. Porque, se a constituição anatômica não permite a formação de uma linguagem com uma dupla articulação de unidades discretas, o corpo nem por isso é menos articulado.(...) Os gestos tornam-se inteiramente transparentes, traduzíveis em significações gerais. O corpo exprime então a linguagem articulada, os seus movimentos finalizados, fala a língua clara das funções sociais. A 'linguagem' do corpo não difere grandemente do que dele dizem os discursos imperativos de todos os gêneros e que moldam os seus movimentos (GIL, 2002, p. 72).

Embora claramente menos reverenciado pelo filósofo, esse corpo que fala, e, na mesma medida, escreve, visto que estamos no campo da produção dos discursos pela palavra, busca organizar experiências em relatos (no nosso ver, não necessariamente arbitrários quanto ao conteúdo, 
ainda que o sejam no que tange à forma). É um corpo-em-arte que opera inevitavelmente na velocidade das sínteses de consciência, sem às quais a comunicação pela palavra não se processa. Não estamos afirmando que todo texto seja orientado por uma estética da lógica e do entendimento, pois, é certo, estaríamos ignorando toda produção dramatúrgica desde as vanguardas históricas até o pós-dramático. Porém, operacionalmente, também é certo que o trabalho com a palavra é pressionado por forças de organização que desejam desenhos comunicantes que encaminham para a palavra, para o código partilhado.

A não-linguagem da Dança, explicada por Gil, é exatamente 0 resultado do trabalho do corpo em desejos outros de produção rumo ao desconhecido da criação. A Dança não busca sentidos, tão mais se potencializa quanto abandona a pretensão de mimese e de se valer de formas narrativas que as transformam numa espécie de irmã enfeitada do Teatro. O âmbito de trabalho do corpo que dança é essencialmente outro. Mas o que surge quando se dança a destruição dos sentidos, o esvaziamento dos gestos e dos movimentos à luz dos atravessamentos energéticos? O bailarino como corpo construtor de um plano de imanência cuja velocidade dos atravessamentos, do processo de virtualização e atualização, excede aquela de codificação e decodificação pela palavra e seus nexos. Como afirma Gil na mesma obra:

\footnotetext{
Porque a Dança cria um plano de imanência, o sentido desposa imediatamente 0 movimento. A Dança não exprime, portanto, o sentido, ela é o sentido, (porque o movimento é o sentido).(...) A Dança constrói o plano de movimento onde o 'espírito e o corpo são um só', porque o movimento do sentido desposa o próprio sentido do movimento: dançar é não 'significar', 'simbolizar' ou 'indicar' significações ou coisas, mas traçar o movimento graças ao qual todos esse sentidos nascem. No movimento dançado, o sentido torna-se ação (GIL, 2002, p. 79).
}

Observe-se que não se trata somente de destruir ou plasmar sentidos, o que manteria a Dança sujeita às lógicas de produção da linguagem. O plano de imanência da Dança produz um campo ao qual nada do sentido escapa à linguagem, porque os movimentos do sentido entram nos próprios movimentos de sentido da Dança em ação, criando seus nexos específicos. 
O gesto do bailarino, criado no plano de imanência e na velocidade específicos da Dança, é o gesto em devir, por isso não significa, não remete, não explica. É um movimento nuvem que nunca se conclui, imediatamente deseja outro desdobrar-se, sem jamais se fechar na significação. As "frases" às quais nos referimos para designar as pequenas partes de uma coreografia, paradoxalmente, não servem para dizer, mas para esquivar.

Nesse processo, o bailarino como corpo depoente passa, às palavras de Gil, de um pensamento sobre o corpo, para um corpo de pensamento, da consciência do corpo para o corpo da consciência. Na Dança, o bailarino eleva sua graduação energética a um ponto que faz com que a consciência do seu corpo, fundamental para sua arte, se amplie para produzir a transformação do pensar em um modo outro, em que a velocidade das informações excede o reconhecimento racional e sua tradução. É um saber indizível, que se processa em territórios diluídos, para o qual as antigas hierarquias da cognição já não oferecem respostas, pois envolve uma reorganização das funções da mente e a destruição do dualismo menteextensão. É como se a consciência baixasse do centro cortical e reintegrasse integralmente o todo complexo que participa do trabalho criador (Gil classifica essa consciência exatamente como consciência infra).

É pelas sínteses criadoras do corpo da consciência como apresentamos até agora que buscamos entender a produção do corpo que dança. E é pela compreensão das singularidades operacionais desse corpo que podemos pensar novas estratégias de interlocução com a produção de dramaturgia. Como equalizar encontros energéticos e sinergéticos possíveis entre tais corpos?

Eis que convém resgatar, nesse contexto, uma perspectiva de dramaturgia em Dança apresentada pela filósofa Charlotte Dubray, que, acreditamos, sugere um trânsito de trabalho potente para os corpos que dançam e aqueles que escrevem. Dubray salienta que, quando a dramaturgia atinge seu espaço final, qual seja, o espaço cênico, ela só existe enquanto atravessada pelas forças visíveis e invisíveis e pelos adensamentos que definem os corpos de dançarinos/atores/performadores e audiência naquele encontro presente. É um ponto de múltiplas atualizações. 
Dessa forma, conforme a filósofa, interrogar a dramaturgia na Dança nos convida a pesquisar a atualização de duas ordens de significações distintas. De imediato, reconhecemos um trabalho cênico como coreografia, mas qual texto ele atualiza? Um elemento se coloca aqui como candidato ao texto: o corpo. Em Dança, a dramaturgia se centra no corpo, que ela designou como sendo o principal lugar de emergência do sentido. Técnico, carnal e emotivo, o corpo se inventa e se conta ao longo de uma coreografia ao grado de um tempo cênico compartilhado. Mas, o que reter desse dom do corpo, qual parte dele, desse vivido tão profundamente inscrito em sua carne o bailarino consente em entregar?

Quando nos pergunta qual texto a coreografia atualiza, cuja resposta é o próprio corpo como plano de imanência, Dubray redimensiona profundamente a complexidade do processo. Ela localiza a dramaturgia como uma construção que se dá em um lugar em suspensão entre os corpos que escrevem e aqueles que dançam, e, vai mais longe: também aqueles que assistem e co-participam energeticamente do encontro-eventoespetáculo, relacionando-a diretamente, com a noção de performatividade contemporânea. Trata-se, pois, de investigarmos quais mecanismos podem fomentar uma produção dessa natureza , qual seja, a de uma dramaturgia da performatividade.

Deleuze nos aponta alguns caminhos quando, relendo a teoria da memória de Bergson, nos apresenta o conceito de memória como um processo, não de retenção da experiência histórica passada, uma ida do sujeito no presente rumo a conjunto de sensações, percepções e afetos passados reconhecidos como um acontecimento específico. Mas, sim, de uma atualização do vivido pelas contingências do presente, em que as lembranças se definem pressionadas pelo conjunto de condições de toda natureza que marca o instante presente específico pelo qual passa o corpo.

Para Deleuze, o virtual, campo da memórias, é o possível constituído em suspensão, mas não um possível como fenômeno estático, e sim um complexo problemático, que chama um processo de resolução: a atualização. É realidade latente, consistente, organizada, autônoma, devinda, que aguarda pela efetivação das relações que lhe transportem da 
suspensão para atualização. Assim, o virtual não se opõe ao real, mas ao atual. Ele contém o real na névoa problemática de tensões e tendências que Ihe identificam, mas cuja resolução não está contida aprioristicamente nessa névoa.

Esse é um ponto fundamental das relações de atualização, e que as distinguem da realização: elas são sempre criadoras. O virtual, a potência em desejo, contém e oferece as possibilidades de relação para definir o real, mas as formas de atualização não são dadas estruturalmente pela possibilidade. Cada estrato carrega suas virtualidades e organiza sua identidade precisamente na maneira como as atualiza e como recria novos virtuais. Dessa forma, todo corpo é um corpo criador, posto que recria sua história toda vez que atualiza suas memórias no presente.

A memória, quando trabalhada pelo corpo-em-arte depoente, dispõe os conteúdos históricos em um trânsito intenso e acelerado entre os conhecimentos apreendidos e em apreensão, a ponto de um se misturar de tal forma ao outro que já não se pode falar em núcleos fechados de experiência armazenada, mas em fluxo de contaminações. O que varia são as molduras estéticas que tais memórias adquirem quando na produção de uma obra de arte, seja uma coreografia, uma personagem dramática, uma performance, etc. Aos distintos enquadramentos que a memória criadora adquire pelo trabalho do corpo-em-arte, denominamos depoimento pessoal. Analisemo-no mais profundamente.

No tempo da criação, o passado irrompe como a força que recupera e revela os subsídios pelos quais o sujeito se oferece aos estímulos do processo. Esses materiais são a fonte de seu depoimento pessoal, são o próprio sujeito transbordando da pele em ações, sons, palavras, e reconstruindo sua história pelas circunstâncias mais ou menos ficcionais de cada processo de criação. É o próprio artista como singularidade em devir que se desfaz e reinventa na criação e estruturação do depoimento a cada apresentação. Mais do que em qualquer outra atividade humana, é o artista da cena que se põe em devir como profissão, se dilui e se reconta infinitamente cada vez que depõe para formar sua obra. 
No depoimento específico do corpo que dança, verificamos um processo que tende radicalmente para a diluição dos agregadores pessoais pelo movimento. O bailarino torna-se fluxo dinâmico de uma memória que não pode ser traduzida senão pelo próprio conjunto de ações/sentido da dança executada naquele instante e nas relações que daí advém. Sua atividade força a ruptura de sentidos, e se choca com a força de agregação da palavra. Daí nasce a atávica querela entre texto e movimento, que tem na produção dramatúrgica em Dança sua crise ampliada

Crise justificada, posto que tratamos de uma disciplina que envolve a criação conjunta de pelo menos dois corpos, e, talvez três ou mais, em dinâmicas bastante distintas. Como equalizar a produção de relatos do bailarino, do dramaturgo e do espectador, se, como deseja Dubray, o tomarmos como parte possível do processo de produção dramatúrgica? Quais danças essas memórias agenciadas podem sintetizar? Com quais desenhos estéticos? Quais mecanismos servem para organizar os materiais?

Cada processo de criação oferecerá as respostas, e arriscarmos regras parece improvável e contraproducente. Parece-nos mais potente entendermos esse diálogo de corpos em estados distintos não tanto como uma disputa de saberes, como, nos parece, tem sucedido com certa freqüência entre os campos, mas como uma negociação, um fluxo de agenciamentos desejosos que permita construir outros corpos pelos quais, finalmente, possa falar essa complexa dramaturgia, agora não mais apenas da Dança, mas da performatividade.

Corpos que dançam, escrevem ou se deslocam para ter uma experiência de co-criar uma obra mesmo que seja na função de audiência são corpos que se colocam voluntariamente no campo da peformatividade, do fluxo das intensidades. As intensidades movimentam os corpos para determinadas zonas conforme a ordem dos desejos, projetam-Ihes ao contato com o que também lhe procura para agenciar interesses, necessidades. Criam uma zona de instabilidade: desterritorializam e reconfiguram os estratos. É pela potência dos desejos que os seres se deslocam, e estabelecem os agenciamentos que os definem em 
determinado recorte, os quais podemos incluir também a criação dramatúrgica.

A dramaturgia, nesse cenário, precisa se reconhecer como uma dramaturgia de campo, da imanência, que precisa considerar não somente a palavra como atualização final do processo, mas o fluxo de virtualização das memórias que ela imediatamente provoca. Não está apenas na palavra como resultado, posto que o processo não termina. A palavra volta para bailarino e, talvez, para público, e se agencia novamente em outras condições, para daí desdobrar novos discursos. Ela se funda no campo suspenso da performatividade como fenômeno que não está só no intérprete, nem só no dramaturgo nem no público apenas, mas no fluxo real da dança das memórias organizadas dinamicamente nos depoimento específico do bailarino e nos agenciamentos com a audiência, em devir.

Uma tarefa que leva o trabalho do dramaturgo a um nível impensável: dar conta não somente do que se diz, mas de seus desdobramentos como parte da obra. No entanto, é este o lugar para onde a condição pósdramática, e de forma mais radical, a Dança como trabalho do corpo da consciência, conduziu essa função em nossos tempos, e da qual já não nos parece mais possível recuar.

\section{REFERÊNCIAS BIBLIOGRÁFICAS}

ALLIEZ, Éric. Deleuze Filosofia Virtual. São Paulo: editora 34, 1996.

AU, Susan. Ballet and Modern Dance. New York: Thames and Hudson, 1988.

BERGSON, Henri. Matéria e Memória. São Paulo: Martins Fontes: 2006.

BOURCIER, Paul. História da Dança Moderna no Ocidente. São Paulo: Martins Fontes, 1987.

CUNNINGHAM, Merce. The Dancer and the Dance. New York: Marion Boyars Inc., 1985. 
DELEUZE, Gilles. Bergsonismo. São Paulo: editora 34, 2001. Mil Platôs Capitalismo e Esquizofrenia. vol. 2. São Paulo: editora 34, 1995.

Mil Platôs Capitalismo e Esquizofrenia. vol 3. São Paulo: editora 34, 1996.

Mil Platôs Capitalismo e Esquizofrenia. vol. 4. São Paulo: editora 34, 1997. . O que é Filosofia?. São Paulo: editora 34, 1992.

FEBVRE, Michele. Dance Contemporaine et Thèatralité. Paris: Chiron, 1995. FÉRAL, Josette. Performance and Theatricality: The Subject Demystified. Modern Drama. New York, v. 25, n. 1, p. 170-181. mar. 1982.

- Teatro, Teoría y Práctica: más allá de las Fronteras. Galerna:Buenos Aires, 2004.

GIL, José. Movimento Total. São Paulo: lluminuras, 2009.

HORST, Louis e RUSSEL, Carol. Modern Dance forms in relation to the other modern arts. New York: Dance Horizons, 1967.

LÉVY, Pierrre. O que é o virtual?. São Paulo: editora 34, 1996.

MARFUZ, Luis César Alves. O Paradoxo da Construção da Personagem na Dança-Teatro de Pina Bausch. Repertório. Salvador, n. 2, p. 30-36, 1999.2.

RODRIGUES, Eliana. A Trajetória Dialética da Dança Pós-Moderna. Repertório. Salvador, n. 2, p. 12-17, 1999.2.

SHAWN, Ted. Every little movement. New York: Witmark and Sons, 1963. 